\title{
A metabolic dysfunction in early murine osteoarthritis
}

\author{
F. P. ALTMAN \\ From the Professorial Unit, Institute of Orthopaedics, Brockley Hill, Stanmore, Middlesex HA7 4LP
}

SUMmARY Male mice of the STR/ORT strain spontaneously develop an osteoarthritic lesion in the medial tibial condyle. The appearance of the lesion is age-related and by about 15 months has affected almost all animals. Histochemical studies of lactate dehydrogenase and succinate dehydrogenase activities have shown that a region of inactive chondrocytes appears in the cartilage of these mice before major histological evidence of degeneration. It is suggested that this may be an early metabolic dysfunction, which subsequently leads to matrix breakdown due to the lack of essential enzyme cofactors.

Clues to the aetiology of osteoarthritis are most likely to be found in a study of the very early stages of the disease process. ${ }^{1}$ This is best achieved in an animal model, where the development of the lesion is well defined. Male mice of the inbred STR/ORT strain consistently develop an osteoarthritic lesion in the knee joint, specifically in the medial tibial condyle. ${ }^{2} 3$ The lesion always occurs first close to the junction of the articular cartilage and the cruciate ligament, and subsequently spreads out across the whole condyle. The lateral condyles are not affected. There is an almost $100 \%$ incidence by the age of about 15 months. The lesion appears to be a result of an instability of the patella, which becomes displaced to the medial side; increased loads are thus transmitted through the medial condyle, and these are thought to initiate the degenerative changes. ${ }^{4}$

Full details of the origins of these mice, from the parent STR/1N strain in the National Institutes of Health, Bethesda, Maryland, USA, have been given. ${ }^{2}$ They have also been extensively studied. ${ }^{3-7}$ In the present studies, they have been used in an attempt to define any metabolic changes which may occur in the chondrocytes before the histological appearance of degenerative changes in the articular cartilage.

\section{Materials and methods}

Male mice of the osteoarthritis-prone STR/ORT strain were used. Age-matched male mice of the normal CBA strain served as controls. The animals were killed by cervical dislocation, and their knee

Accepted for publication 20 August 1980.

Correspondence to Dr Altman. joints removed and embedded in gelatin prior to freezing in $n$-hexane at $-70^{\circ} \mathrm{C} .^{8}$ Cryostat sections were prepared at a thickness setting of $18 \mu \mathrm{m}$ in a Bright's cryostat fitted with a Jung rotary microtome and a tungsten-carbide tipped knife. ${ }^{9}$ The sections were picked up on coverslips and incubated for the histochemical demonstration of lactate dehydrogenase (LDH) and succinate dehydrogenase (SDH). ${ }^{10}$ Incubation media were made up in $140 \mathrm{mM}$ HEPES buffer containing $32 \%(\mathrm{w} / \mathrm{v})$ polyvinyl alcohol (grade G04/140). ${ }^{11} 12$

LDH media contained: $10 \mathrm{mg} / \mathrm{ml}$ sodium-DLlactate, $2 \mathrm{mg} / \mathrm{ml} \mathrm{NAD,} 3 \mathrm{mg} / \mathrm{ml}$ neotetrazolium chloride, and $0.2 \mathrm{mg} / \mathrm{ml}$ phenazine methosulphate, at a final $\mathrm{pH}$ of $8 \cdot 0$. SDH media contained $10 \mathrm{mg} / \mathrm{ml}$ sodium succinate, $3 \mathrm{mg} / \mathrm{ml}$ BPST (a new tetrazolium salt), ${ }^{1314}$ and $0.2 \mathrm{mg} / \mathrm{ml}$ phenazine methosulphate, at a final $\mathrm{pH}$ of $8 \cdot 0$. Both media were saturated with oxygen-free nitrogen before use. (SI conversion: $\mathrm{g} / \mathrm{l}=\mathrm{mg} / \mathrm{ml}$.)

Incubations were performed at $37^{\circ} \mathrm{C}$ in Perspex rings placed over the sections. The rings were closed with coverslips during the incubations. After 10 minutes the rings were removed from the sections, which were allowed to drain vertically in a rack. The reactions were stopped by carefully pouring a solution of polyvinyl alcohol, at a $\mathrm{pH}$ of about 2 . over the sections (the sections were found to disintegrate after conventional washing in water), The sections were mounted in an aqueous mountant, such as Farrant's, prior to examination.

\section{Results}

Preliminary results ${ }^{15}$ had indicated the presence of inactive chondrocytes in that region of the articular 
cartilage where the osteoarthritic lesion always begins. By contrast, both LDH and SDH activities were generally evenly distributed throughout the condyles of control mice and also in the lateral condyles of the disease-prone mice. Fig. 1 shows the development of such an inactive region in 7 serial sections from a 16-week-old STR/ORT mouse, with
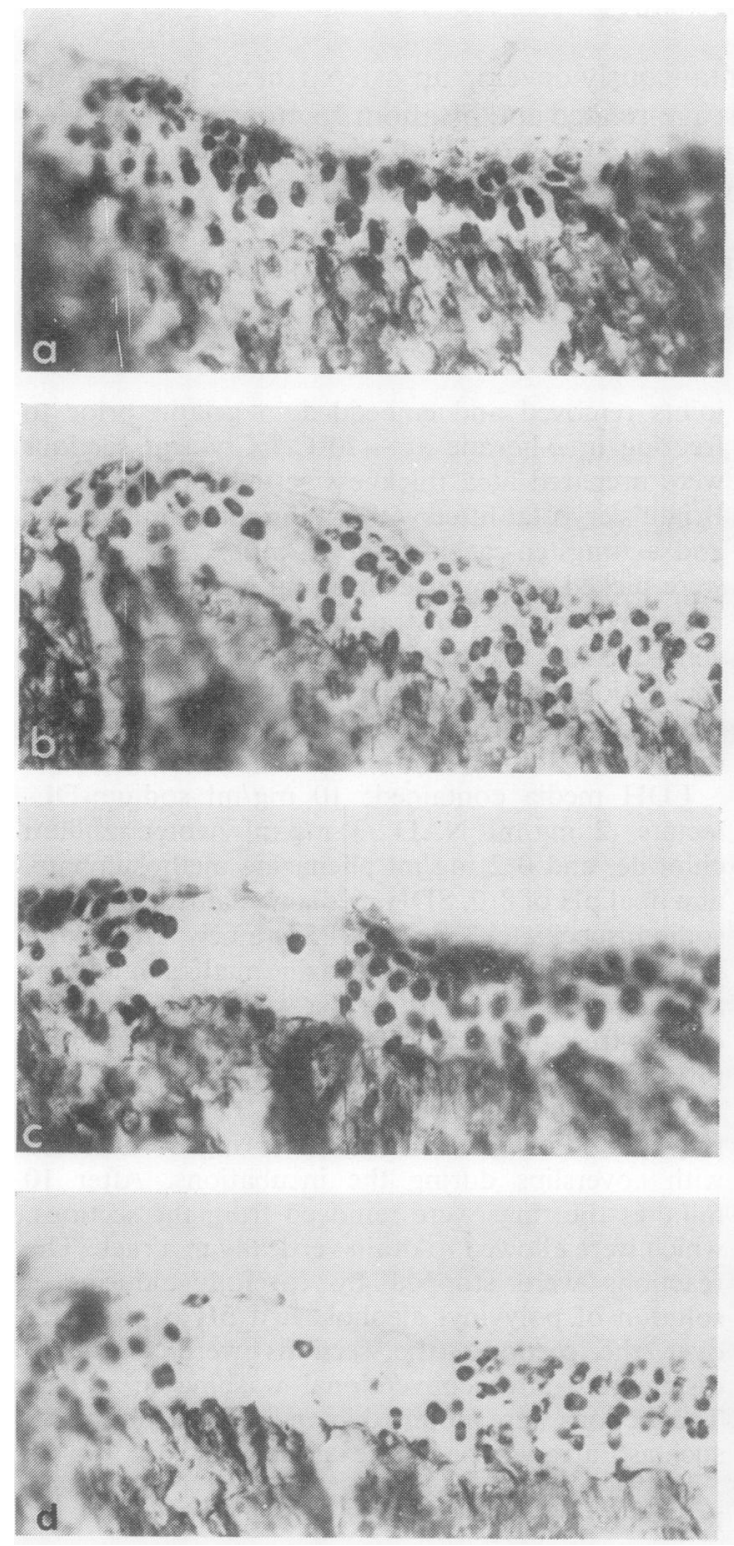

no apparent signs of degenerative changes in terms of surface fibrillation. The sections were alternately reacted for LDH and SDH.

In Fig. 1 (a) LDH activity is evenly distributed. Fig. 1 (b) shows SDH activity, with a small region of inactivity. This region has increased in size in Fig. 1 (c), which shows LDH activity, although one active
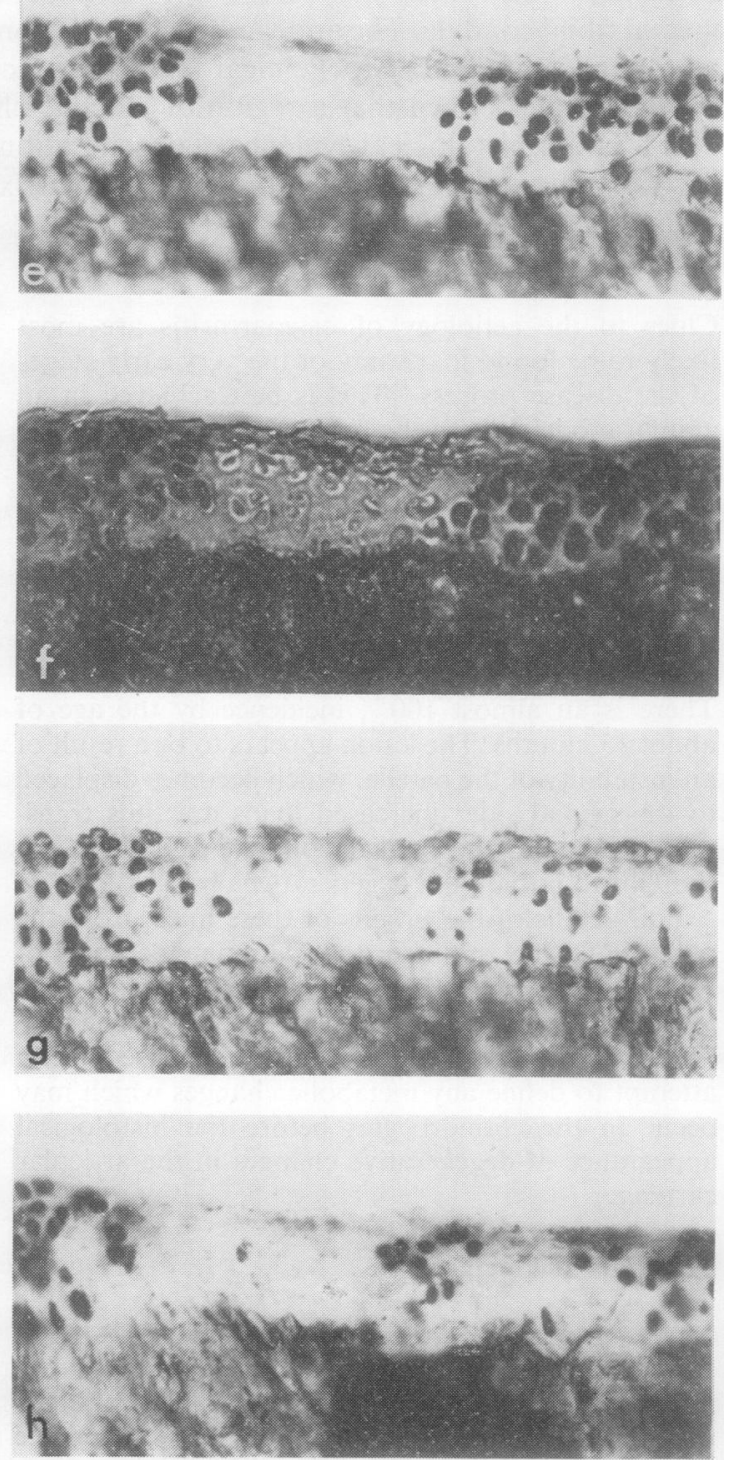

Fig. $1 \mathrm{LDH}$ and SDH activities in serial sections of the medial tibial condyle of a 16-week-old STR/ORT mouse (×340). (a) $L D H$; (b) $S D H$; (c) $L D H$; (d) $S D H$; (e) $L D H$; (f) same field as in (e) but photographed with the condenser diaphragm stopped down; (g) $S D H$; (h) $L D H$. 
Table 1 Inactive $L D H / S D H$ regions in osteoarthritisprone mice of various ages

\begin{tabular}{|c|c|c|}
\hline Age (weeks) & Osteoarthritis grade* & Inactive $L D H / S D H$ region \\
\hline $2 \frac{1}{2}$ & 0 & No \\
\hline 3 & 0 & No \\
\hline 5 & 0 & No \\
\hline 7 & 0 & No \\
\hline 8 & 0 & No \\
\hline 9 & 0 & No \\
\hline 9 & 0 & YES \\
\hline 9 & 0 & YES \\
\hline 10 & 0 & No \\
\hline 11 & 1 & YES \\
\hline 12 & 0 & No \\
\hline 12 & 2 & YES \\
\hline 12 & 2 & YES \\
\hline 13 & 0 & YES \\
\hline 13 & 0 & No \\
\hline 13 & 2 & YES \\
\hline 14 & 1 & YES \\
\hline 15 & $\mathbf{0}$ & NO \\
\hline 16 & 0 & YES \\
\hline 16 & 1 & YES \\
\hline 16 & 1 & YFS \\
\hline 17 & 2 & YES \\
\hline 17 & 1 & YES \\
\hline 17 & $!$ & YES \\
\hline 18 & 1 & YES \\
\hline 19 & 3 & YES \\
\hline 20 & 0 & YES \\
\hline 23 & 2 & YES \\
\hline 28 & 2 & YES \\
\hline
\end{tabular}

*Arbitrary grading based on. ${ }^{2} 0=$ normal; $1=$ slight fibrillation; $2=$ more extensive fibrillation; $3=$ chunks of cartilage lost; $4=$ complete loss of cartilage down to subchondral bone.

cell remains. The inactive region spreads further across the condyle in subsequent sections. Fig. 1 (f) shows the same field as in Fig. 1 (e), but photographed with the condenser diaphragm stopped down. It shows quites clearly that cells are still present in the inactive region. This effect has been observed several times in the cartilage from the medial tibial condyle of STR/ORT mice, but never in cartilage from the lateral condyle of the same animal, or from agematched control mice. Table 1 gives some data on the appearance of this effect with age and degree of severity of osteoarthritis.

The findings in the medial tibial cartilage can therefore be summarised as follows: (i) all animals with some degree of osteoarthritis had an inactive region; (ii) some animals with no apparent osteoarthritis (grade 0 ) also had an inactive region; (iii) inactive regions were not observed in animals under 9 weeks of age.

\section{Discussion}

The first histological change which is seen to occur in the STR/ORT mice is a loss of staining in the deeper zones of the cartilage, due to a loss of mucopolysaccharide. ${ }^{3}$ The affected region of cartilage then becomes progressively acellular, and fibrillations appear in the cartilage surface. The results presented here suggest that there is a time in the early stages of this process, perhaps before cell death occurs, when the chondrocytes have lost some of their enzyme activity. Fig. 1 (e) shows a large completely inactive region in an otherwise active population of chondrocytes. Fig. 1 (f) shows that this inactive region still contains cells in their lacunae. It is tempting to suggest that this enzyme depletion is a very early metabolic change, which precedes any histological change, though this has yet to be confirmed. Other enzymes have not yet been tested, so it is not known to what extent this inactivity applies to other reactions. However, a depletion of LDH alone could account for matrix degeneration, as is indicated in Fig. 2.

Articular cartilage has a glycolytic rate comparable to that of other tissues, but its oxygen uptake is very low. ${ }^{16}{ }^{17}$ Chondrocytes therefore depend largely on anaerobic respiration for the reoxidation of NADH generated during glycolysis, that is, on the lactate dehydrogenase reaction. Apart from its requirement in glycolysis, NAD is also specifically required as a coenzyme for 2 oxidative reactions involved in the biosynthesis of UDP sugars needed for glycosaminoglycan (GAG) production, namely, UDP glucose dehydrogenase and UDP glucose epimerase. The key role of lactate dehydrogenase in this sequence now becomes clear. If this enzyme is lacking, NADH will build up, and glycolysis, and glycosaminoglycan

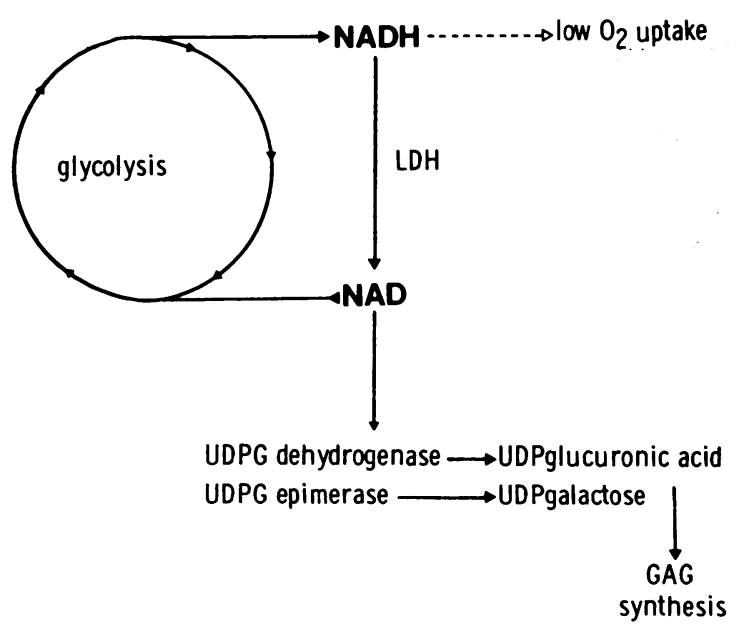

Fig. 2 Interrelationships between glycolysis and UDP sugar metabolism, showing the dependence of glycosaminoglycan $(G A G)$ biosynthesis on a supply of $N A D$ generated by lactate dehydrogenase $(L D H)$. 
biosynthesis, will cease. In this context it is of interest that the intra-articular injection of iodoacetate, a potent inhibitor of glycolysis, has been shown to induce an experimental osteoarthritis in hens. ${ }^{18}$ Furthermore, it has been shown that NADH is a potent inhibitor of the UDP glucose epimerase reaction, ${ }^{19}$ so even if there should be sufficient NAD available in the cell this reaction would still be affected owing to the inhibitory action of the accumulated NADH. One may then postulate that the reduced biosynthetic capability of the chondrocytes will lead to matrix weakness, and breakdown under even slightly increased stresses. Repair of such early degenerative changes would be impaired, and osteoarthritis would gradually develop.

Recently, and independently, a similar focal loss of oxidative enzyme activity has been reported to occur in the knee joint cartilage of osteoarthritic mice of the C57B1 strain. ${ }^{20}$ This loss of activity extended to lactate dehydrogenase, succinate dehydrogenase, NADH diaphorase, glucose 6 phosphate dehydrogenase, NADPH diaphorase, cytochrome oxidase, and UDP glucose dehydrogenase, and seems to represent a far-reaching metabolic disturbance.

Studies are at present in progress to assess the viability of the chondrocytes in the inactive regions in the light and electron microscope.

The financial support of the Arthritis and Rheumatism Council is gratefully acknowledged. I should also like to thank Dr S. Y. Ali for helpful discussions during the course of this work.

\section{References}

1 Ali S Y. New knowledge of osteoarthrosis. J Clin Pathol 1978; 31 : (suppl.) (Roy. Coll. Path.) 12: 191-199.

2 Walton M. Degenerative joint disease in an inbred strain of mouse. Ph. D. thesis, University of London, 1975.

3 Walton M. Degenerative joint disease in the mouse knee; histological observations. J Pathol 1977; 123: 109-22.
4 Walton M. Patella displacement and osteoarthrosis of the knee joint in mice, J Pathol 1979; 127 : 165-71.

5 Walton M. Degenerative joint disease in the mouse knee; radiological and morphological observations. J Pathol 1977; 123: 97-107.

6 Walton M. Studies of degenerative joint disease in the mouse knee joint; scanning electron microscopy. $J$ Pathol 1977; 123: 211-7.

7 Walton M, Elves M W. Bone thickening in osteoarthrosis. Observations of an osteoarthrosis-prone strain of mouse. Acta Orthop Scand 1979; 50: 501-6.

8 Altman F P. A gelatin embedding technique as an aid in the preparation of unfixed cryostat sections. Histochem $J$ 1978; 10: 617-20.

9 Johnstone J J A. The routine sectioning of undecalcified bone for cytochemical studies. Histochem $J$ 1979; 11 : 359-65.

10 Chayen J, Bitensky L, Butcher R. Practical Histochemistry. London: Wiley, 1973.

11 Altman F P. The use of a new grade of polyvinyl alcohol for maintaining tissue integrity during histochemical incubations. Histochemistry $1971 ; 28$ : 236-42.

12 Henderson B, Loveridge N, Robertson W R. A quantitive study of the effects of different grades of polyvinyl alcohol on the activities of certain enzymes in unfixed tissue sections. Histochem $J$ 1978; 10: 453-63.

13 Kalina M, Plapinger R E, Hoshino Y, Seligman A M. Non-osmophilic tetrazolium salts that yield osmiophilic formazans for ultra-structural localisation of dehydrogenase activity. J Histochem Cytochem 1972; 20: 685-95.

14 Altman F P. The quantification of formazans in tissue sections by microdensitometry. II. The use of BPST, a new tetrazolium salt. Histochem $J$ 1976; 8: 501-6.

15 Altman F P. Metabolic changes associated with osteoarthritis. In: Pattison J R, Bitensky L, Chayen J, eds. Quantitive Cytochemistry and its Applications. London: Academic Press, 1979: 99-104.

16 Bywaters E G L. The metabolism of joint tissues. J Pathol Bacteriol 1937; 44: 247-68.

17 Stockwell R A, Meachim C. The chondrocytes. In: Freeman M A R, ed. Adult Articular Cartilage. Kent: Pitman Medical, 1979: 69-144.

18 Kalbhen D A. In: Nuki G, ed. The Aetiopathogenesis of Osteoarthrosis. Kent: Pitman Medical, 1980: 123-38.

19 Phelps C, Stevens R. Nucleotide sugar metabolism in glycosaminoglycan biosynthesis. Ann Rheum Dis 1975; 34 (suppl 2): 48-51.

20 Pataki A, Rüttner J R, Abt K. Age-related histochemical and histological changes in the knee joint cartilage of C57B1 mice and their significance for the pathogenesis of osteoarthrosis. Exp Cell Biol 1980; 48: 329-48. 